\title{
ИСТОРИЧЕСКИЙ ОПЫТ ФОРМИРОВАНИЯ ЯЛТИНСКО-ПОТСДАМСКОЙ СИСТЕМЫ МЕЖДУНАРОДНЫХ ОТНОШЕНИЙ
}

В статье фрагментарно показан процесс становления послевоенной системы международных отношений, в основу которой были положены договоренности союзников по антигитлеровской коалиции (СССР, США и Великобритании), достигнутые ими в ходе совместной работы на Ялтинской и Потсдамской международных конференциях. Отмечается способность союзников договариваться, искать компромиссы в условиях совместной борьбы против общего врага. Раскрывается картина послевоенной Германии, судьба немецкого населения и основных военных преступников, что непременно учитывалось в переговорном процессе между союзниками. На этом фоне авторы статьи обращаются к проблеме трансформации послевоенной системы безопасности в современный период, выражают мнение, что эта проблема обусловлена демонтажем биполярного противостояния, конец которому был положен развалом Советского Союза и распадом социалистического содружества. Этот процесс происходит в условиях са- моидентификации новых акторов международных отношений и попыток ведущих западных держав установить выгодные для них правила внешнеполитического поведения. Авторы делают вывод о необходимости сохранения исторической памяти, которая поможет повысить уровень ответственности политиков перед мировой общественностью. Необходимость решения современных проблем человечества, таких как предотвращение угрозы ядерной войны, борьба с международным терроризмом, предотвращение региональных военных конфликтов доказывают необходимость сотрудничества крупнейших ядерных держав в мире. С этой точки зрения актуализируется изучение исторического опыта взаимодействия стран антигитлеровской коалиции в военный и послевоенный периоды.

Ключевые слова: антигитлеровская коалиция, миропорядок, система международных отношений, сотрудничество, конфронтация.

\section{HISTORICAL EXPERIENCE OF FORMING YALTA-POTSDAM SYSTEM OF INTERNATIONAL RELATIONS}

The article shows some parts of the process of establishing post-war system of international relations, which was based on the agreements of the Allies (the Soviet Union, the US and the UK) achieved at the Yalta and Potsdam international conferences. The ability of allies to negotiate, to seek compromises in a joint struggle against the common enemy is noted. The picture of the post-war Germany and the fate of the German population and the major war criminals is shown. It was certainly taken into account in the negotiations between the allies. Against this background, the authors address the issue of transformation of post-war security in the modern period and express the view that the problem was caused by dismantling of the bipolar confrontation, the end of which was placed by the collapse of the Soviet Union and the collapse of the socialist community. The process took place under conditions of self-identification of new actors in international relations and the attempts of the leading western powers to establish the rules of international conduct that could be profitable for them. The authors conclude that there is necessity to preserve the historical memory, which will help raise the level of political responsibility before the world community. The need to address contemporary problems of humanity, such as the prevention of the threat of nuclear war, the fight against international terrorism, the prevention of regional military conflicts demonstrate the need for cooperation of the largest nuclear powers in the world. From this point of view, it is updated study of the historical experience of the interaction of the anti-Hitler coalition in the war and post-war periods.

Key words: anti-Hitler coalition, world order, the system of international relations and cooperation, confrontation.

рашние союзники по антигитлеровской коалиции сразу же после победы во Второй мировой войне превратились в противников, подтверждая тезис - том, что союзнические отношения возможны лишь в военной области, перед лицом общей угрозы. Такие же отношения в политике, скорее, являются исключением, нежели нормой международной жизни. Тем не менее, сначала на Ял- 
тинской, а затем и на Потсдамской конференциях главам США, Великобритании и СССР удалось договориться о коренных изменениях в расстановке сил в мире, установить новый миропорядок, который на десятилетия исключал возможность возрождения милитаризма в Европе. Не случайно поэтому, результаты работы названных международных форумов по сей день сохраняют свою актуальность, вызывают неподдельный интерес со стороны политиков, общественности, исследователей различных научных дисциплин и направлений.

Правда, в последнее время все чаще и чаще слышатся призывы к пересмотру итогов Второй мировой войны, в частности тех самых исторических решений, которые принимались в Ялте и Потсдаме и прежде всего в пользу Советского Союза. Так, например, президент США Дж. Буш в своем выступлении по поводу вступления Литвы в НАТО в ноябре 2002 г. особо подчеркнул, что настала пора стереть границы, «начертанные диктаторами» и забыть наследие Ялты. Известный специалист в области международных отношений $Н$. А. Нарочницкая объяснила эти слова американского президента стремлением провести ревизию смысла и духа борьбы с фашизмом, забыть о союзническом долге времен сотрудничества в рамках антигитлеровской коалиции. Примечательно также, что современных западных руководителей не устраивает, в первую очередь, те территориальные решения, которые принимались в пользу советского государства. Сегодня эти решения оцениваются ими не иначе как следствие экспансионистских устремлений руководства СССР $[4$, с. 66].

Речь идет, в частности, о правомерности вхождения в состав Советского Союза Калининградской области, в то время как никто из западных политиков не вспоминает, например, факт расширения границ Польши за счет Силезии. Не вызывает у них сомнений и современная франко-итальянская граница, статус Додеканезских островов и многие другие административно-территориальные изменения, произошедшие после окончания Второй мировой войны. Такая избирательность Запада заставляет вновь обращать внимание его представителей на вопросы истории, без знания которых невозможно понять события настоящего и будущего.

Как известно, ялтинско-потсдамские решения великих держав, членов антигитлеровской коалиции непосредственно касались вопросов послевоенного урегулирования международных отношений и обеспечения европейской безопасности. Соглашение, достигнутое и подписанное лидерами США, Великобритании и СССР в Потсдаме, в сущности, представляло собой протокол международной конференции, и в этой связи оказалось весьма уязвимым с правовой точки зрения. Несмотря на это, данное соглашение на долгие годы стало основополагающим правовым актом, который был положен в основу строительства новой Европы и нового миропорядка. При достижении этого соглашения выявились все противоречия и разногласия, существовавшие между участниками антигитлеровской коалиции. Однако в то время все они проявили единодушие в решении вопросов оккупации Германии и реализации на ее территории денацификационных мероприятий в социальной, политической и экономической сферах. США, СССР, Великобритания и присоединившаяся к ним Франция взяли на себя ответственность не только за будущее германского народа, но и всего цивилизованного мира.

Необходимо отметить, что за всю многовековую историю человечества ни одно государство и ни одна военно-политическая коалиция не ставили перед собой аналогичных целей. До 1945 г. история не знала прецедентов полного уничтожения политической системы экономически развитого государства, несмотря на то, что войны являлись постоянными спутниками эволюции человеческого общества. Однако ранее территории, захваченные военным путем, использовались чаще всего для расширения сырьевого, экономического или трудового потенциала страны - победителя, а также для увеличения ее территории. Державы антигитлеровской коалиции перед всем человечеством взяли на себя обязательства полностью изменить характер и структуру германской государственности, принять все необходимые меры к искоренению истоков нацизма и милитаризма и возвращению немецкого народа в европейское и мировое сообщество.

Приступив к практической реализации достигнутых договоренностей, союзники столкнулись, прежде всего, с проблемой стихийной миграции населения, социальной, хозяйственной и бытовой неустроенностью жизни основной массы людей, всеобщим обнищанием. Хаос и страх породили многотысячные потоки беженцев и переселенцев, устремленные вглубь страны. Немцы в состоянии полной безысходности покидали территории, отошедшие к Польше и Советскому Союзу. Согласно официальной статистике, в начале мая 1945 г в Германии было учтено почти 1,1 млн перемещенных лиц [2, л. 65, 70, 82, 88].

Очевидцы свидетельствовали, что немцы, которым удалось пережить окончание войны, находились в подавленном состоянии. Их жизнь в то время определялась единственно желанным стремлением найти пропитание, жилье и разыскать разбросанных войной родственников. Общественное сознание немецкого населения было наполнено, с одной стороны, чувством вины за развязанную войну и принесенные другим народам страдания, с другой, - страхом перед победителями. Угнетающе действовали также разрушения, которых Германия не знала со времен Тридцатилетней войны. Многие города и сельские населенные пункты были частично или полностью разрушены в результате массированных бомбардировок и лежали в руинах, промышленное производство фактически прекратилось, страна полностью лишилась транспортной инфрраструктуры и большей части коммуникаций, некогда являвшихся гордостью немецкой нации. 
Главным средством перемещения беженцами скудного домашнего скарба являлись кустарные тачки и уцелевшие детские коляски.

В условиях послевоенного хаоса союзникам предстояло провести кардинальную реконструкцию социально-политической жизни страны, фундаментально и надолго изменить не только государственный статус Германии, но и мировоззрение людей, собственно говоря, научить их жить в мирных условиях сотрудничества с другими народами. Естественно, что первое время мирной жизни требовали, прежде всего, обеспечения минимальных потребностей гражданского населения в продуктах и товарах первой необходимости, восстановления системы продовольственного снабжения. Эта задача сначала легла на плечи военных комендантов, недавно являвшихся боевыми офицерами, не знакомыми с хозяйственно-административной деятельностью. Поэтому их решения порой выходили за рамки указаний сверху и не всегда адекватно отражали реалии послевоенных будней. А. Ю. Ватлин довольно точно представил реальную картину побежденной Германии, отразив при этом общественные настроения немецкого населения. По его словам, в «час ноль немецкой истории состояние умов было под стать хаосу на улицах германских городов». Германия превратилась в подобие обанкротившегося предприятия и стала объектом внешнего управления. После такого поражения не оставалось никаких шансов на возрождение реваншистских настроений, «нельзя было спрятаться за легенду о непобедимой немецкой армии...» $[1$, с. 136]. Несостоятельными оказались и надежды на «коричневое» подполье, наличие которого декларировалось предводителями рейха. Люди воочию убедились, что все фанатично настроенные сторонники национал-социализма вдруг исчезли с политической арены, оставив без защиты только сбитых с толку «случайных попутчиков», отказывавшихся верить в то, что произошло. Потсдамский тезис о «коллективной вине» немецкого народа за преступления фашистского режима, которая лежала в основе неизбежной оккупации страны, не признавался общественным мнением", но оно настойчиво продолжало искать ответ на вопрос о причинах катастрофы [1, с. 137]

Союзникам по антигитлеровской коалиции в рамках сотрудничества в области денацификации предстояло тщательно разобраться с тем, кто был «обманутой жертвой» или «сбитым с толку попутчиком», а кто использует эти маски для сокрытия своих преступлений. К слову сказать, что именно в этом направлении совместной деятельности на территории Германии интересы союзников переплетались очень тесно, поэтому и сотрудничество отличалось высоким уровнем конструктивности, по крайней мере, на начальном этапе. Как известно, еще на Ялтинской конференции был учрежден Союзнический контрольный совет, на который возлагались функции оперативного управления Германией. На основе консенсуса данный орган должен был принимать решения по самым важным для всех оккупацион- ных зон вопросам. В первую очередь, были распущены структурные организации НСДАП всех уровней, не только активным функционерам, но и рядовым членам партии запрещалось занимать государственные посты. Непримиримые национал-социалисты подвергались репрессивному воздействию: арестам и интернированию. В первые месяцы после победы во всех четырех зонах оккупации было арестовано более 270 тысяч немцев, прошлое которых вызывало у новой власти определенное сомнение. Многих из них ожидал справедливый суд.

В исследованиях последнего времени нередко можно встретить тотальные обвинения в адрес советских представительств в Германии, которые якобы без разбора мстили всем немцам за лишения и потери, которые принесла германская агрессия народам СССР. Но здесь необходимо учитывать, что меры оккупационных властей в этом плане мало чем отличались друг от друга. В американской зоне, например, проводилось сплошное анкетирование взрослого населения, с помощью которого облегчался поиск функционеров прежнего режима.

Итогом совместной деятельности союзников в области денацификации стал Нюрнбергский судебный процесс, открывшийся 20 ноября 1945 г. Впервые в международной юридической практике он выдвинул обвинения в «преступлениях против мира и человечества». На скамье подсудимых оказались двадцать два военных преступника из числа высшего руководства Германии и командования вермахта, в том числе Г. В. Геринг, Р. В. Гесс, К. Дениц, В. Б. Кейтель, Ф. Папен, И. фон Риббентроп, А. Шпеер и другие. Судебное разбирательство длилось около года и завершилось в середине октября 1946 г. казнью главных обвиняемых. После этого состоялось еще двенадцать процессов, на каждом из которых вскрывались все новые и новые факты жестокой действительности нацистского режима, не говоря уже о судах над различными военными чинами Германии в других странах Европы, на территории которых они совершали свои злодеяния [5].

Попытаемся проследить хронологию советских инициатив в отношении ответственности военных преступников. Еще в октябре 1942 г. было опубликовано заявление советского правительства, которое признавало необходимым «безотлагательное предание суду специального международного трибунала и наказание по всей строгости уголовного закона любого из главарей фашистской Германии». Через год Советский Союз подготовил декларацию об ответственности гитлеровцев за совершенные зверства во время войны. Она была подписана главами великих держав - членов антигитлеровской коалиции И. Сталиным, Ф. Рузвельтом и У. Черчиллем. Данный документ являлся предупреждением германскому командованию и руководству рейха о неизбежной ответственности, которую рано или поздно понесут военные преступники. Основные из них, как указывалось в декларации, «будут наказаны совместным решением правительств-со- 
юзников». На конференции в Ялте это намерение получило подтверждение, а на встрече в Потсдаме советская делегация внесла на рассмотрение проект решения «О суде над главными военными преступниками». Он вошел в качестве дополнений в соответствующий британский документ. Союзники сделали совместное заявление о том, что они считают делом «огромной важности, чтобы суд над этими главными преступниками начался как можно скорее» [6, с. 457].

На коноеренции в Потсдаме было принято также решение опубликовать список главных военных преступников Германии не позднее $1 \mathrm{ceн-}$ тября 1945 г. В соответствии с существовавшей договоренностью все эти принципы должны были быть обязательными для всех сторон до тех пор, пока они не будут заменены другими межсоюзническими решениями.

Документы и материалы заседаний и особенно записи бесед между лидерами держав - членов антигитлеровской коалиции свидетельствуют о том, что, несмотря на все договоренности, на форумах и встречах по послевоенному урегулированию велись активные дипломатические бои, которые, в конце концов, превратились в холодную войну. И уже в октябре 1945 г. советское руководство сделало вывод о жестком противодействии союзников: «Пока шла война... миллионы людей гибли на фронте, у Советского и Британского правительства были споры, но они сговаривались. Советский Союз был нужен. Как только война окончилась, против Советского Союза принимаются всякие меры». Когда на Ялтинской, а затем и на Потсдамской конференциях советской делегацией был поставлен вопрос о возвращении Карca, Ардагана, оккупированных Турцией в 1918 г., Великобритания и США высказались против, хотя в середине войны это требование они считали вполне правомерным, поскольку не затрагивало «ничего более того, что ранее принадлежало России» $[6$, с. 158,159$]$.

Постепенно отчуждение союзников друг от друга усиливалось, курс на противодействие требованиям и инициативам СССР стал более откровенным после принятия в западных зонах 31 декабря 1949 г. закона об освобождении от наказания отдельных категорий военнослужащих вермахта, осужденных за военные преступления. В новой редакции закон был принят в 1954 г. и ознаменовал собой свертывание денацификации.

Изложенное свидетельствует о том, что западные союзники забыли о своих же обещаниях и договоренностях, амнистировав или досрочно освободив большую часть осужденных нацистских преступников. Эти исторические факты во многом способствовали углублению противоречий между Востоком и Западом и ускорили наступление эпохи “холодного противостояния». В то время западные державы больше всего беспокоили «территориальные» результаты победы, но решения, которые были приняты в Ялте и Потсдаме, сдерживали их устремления. Вот почему и сегодня ялтинско-потсдамская си- стема европейской безопасности находится под прицелом ревизионистски настроенных кругов в Прибалтике, Польше и ряде других стран. В угоду достижения своих целей они представляют освобождение их собственных территорий Красной Армией агрессией и советской оккупацией, не замечая при этом своих приобретений. В этом смысле вспоминаются слова Н. Я. Данилевского по поводу «стона о разделе Польши», автор сравнивал его с отношением Европы к захвату Шлезвиг-Гольштейна: «Будет ли Шлезвиг-Гольштейн датским или германским, он все-таки останется европейским... Но как дозволить распространяться влиянию чуждого, враждебного, варварского мира, хотя бы оно распространялось на то, что... принадлежит этому миру? Не допускать до этого - общее дело всего, что только чувствует себя Европой» [3, с. 41].

Эти слова весьма актуальны для современных международных отношений. Если во второй половине XX века западные державы раздражали в основном территориальные межсоюзнические решения в пользу СССР, то сегодня они стремятся полностью разрушить сложившуюся послевоенную систему международных отношений. Современная политическая практика пополнилась такими механизмами реализации национальных интересов западных стран, как санкции, провокации, откровенная ложь, что отнюдь не способствует установлению доверительных отношений между странами и стабилизации международного сотрудничества.

Ялтинско-потсдамская система безопасности действительно нуждается в корректировке в силу произошедших изменений, и этот процесс уже идет. Причина видится не только в смене биполярного мироустройства на однополярный мир в результате развала СССР, распада социалистического содружества, объединения Германии, раскол которой и обусловил появление ялтинско-подстамской системы. Этого требует, прежде всего, достигнутый уровень развития многих государства мира, углубляющиеся тенденции глобализации, расширение взаимодействия и многие другие факторы. Не трудно заметить, что в современной мировой политике значительно повысилась роль межгосударственных объединений и коалиций, на передовые позиции выходит ряд развивающихся стран, которые способнь конкурировать с традиционными центрами влияния [7]. Эти две тенденции составляют каркас новой системы международных отношений, но процесс трансформации этой системы еще не завершился. Он нуждается в концептуализации, что происходит очень тяжело, несмотря на то, что основные направления этого процесса очевидны: обеспечение стабильности в международных делах; расширение экономического и всех видов гуманитарного сотрудничества; сохранение целостности и безопасности государств различных континентов; создание условий для динамичного внутреннего развития всех участников международных отношений. 
Однако США продолжают настаивать на своей исключительности и пытаются диктовать всему миру новые правила игры. Хотелось бы заметить по этому поводу, что в современном мире любая ревизия исторических реалий недопустима, это не только вызов исторической памяти о совместной борьбе и общей победе, это создание усло- вий для возникновения новых мировых конфликтов, для роста напряженности и недоверия между странами и народами. Чтобы избежать этого необходимо, прежде всего, повысить беспрецедентно низкий уровень ответственности лидеров целого ряда западных государств перед мировой общественностью.

\section{Источники и литература}

1. Ватлин А. Ю. Германия в XX веке. М.: РОССПЭН, 2002. 336 с.

2. Государственный архив Российской Федерации (ГАРФ). Ф. 9408. Оп. 1. Д. 10.

3. Данилевский Н. Я. Россия и Европа: взгляд на культурные и политические отношения славянского мира к германо-романскому. СПб.: Книга, 1995. 574 с.

4. Нарочницкая Н. А. За что и с кем мы воевали. М.: Минувшее, 2005.80 с.

5. Нюрнбергский процесс. Сборник материалов. В 8-ми т. Т.З. М.: Юридическая литература, 1989. 656 с

6. Советский Союз на международных конференциях периода Великой Отечественной войны 1941-1945 гг. Сборник документов. В 6-ти т. Т.6: Берлинская (Потсдамская) конференция руководителей трех союзных держав - СССР, США и Великобритании (17 июля - 2 августа 1945 г.). М.: Политиздат, 1984. 511 с.

7. Современные международные отношения // URL: https://businessman.ru/new-sovremennye-mezhdunarodnyeotnosheniya-sistema-mezhdunarodnyx-otnoshenij.html (Дата обращения: 17.04.2018).

\section{References}

1. Vatlin A.Yu. Germaniya v XX veke (Germany in the Twentieth Century). Moscow: ROSSPEHN, 2002. 336 p. (In Russian).

2. State archive of Russian Federation (GARF). F.9408. Inv.1. D.10. (In Russian).

3. Danilevskij N. Ya. Rossiya i Evropa: vzglyad na kul'turnye i politicheskie otnosheniya slavyanskogo mira k germanoromanskomu (Russia and Europe: A Look at the Cultural and Political Relations of the Slavic World to the Germanic-Romance). St.Petersburg: Kniga, 1995. 574 p. (In Russian).

4. Narochnickaya N. A. Za chto i s kem my voevali (For What and With Whom We Were at War). Moscow: Minuvshee, 2005. 80 p. (In Russian).

5. Nyurnbergskij process. Sbornik materialov (The Nuremberg Trials. The Collection of Materials). In 6 Vols. Vol. 3. Moscow: YUridicheskaya literatura, 1989. 656 p. (In Russian).

6. Sovetskij Soyuz na mezhdunarodnyh konferenciyah perioda Velikoj Otechestvennoj vojny 1941-1945 gg. Sbornik dokumentov. V 6-ti t. T. 6: Berlinskaya (Potsdamskaya) konferenciya rukovoditelej trekh soyuznyh derzhav - SSSR, SSHA i Velikobritanii (17 iyulya -2 avgusta $1945 \mathrm{~g}$.) (The Soviet Union at International Conferences during the Great Patriotic War of 1941-1945. Collection of Documents. In 6 vols 6: Benlin (Potsdam) Conference of the Leaders of the Three Allied Powers - the USSR, the USA and Great Britain (17 July - 2 August 1945). Moscow: Politizdat, 1984. 511 p.

7. Sovremennye mezhdunarodnye otnosheniya (Modern International Relations) URL: https://businessman.ru/newsovremennye-mezhdunarodnye-otnosheniya-sistema-mezhdunarodnyx-otnoshenij.html. (Accessed: 17.04.2018). 